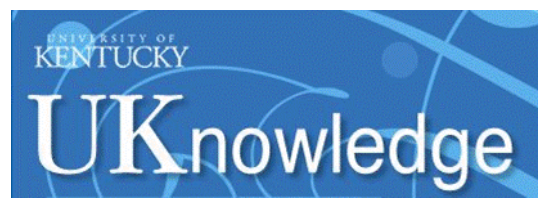

University of Kentucky

UKnowledge

\title{
Prediction of Self-Actualization in Male Participants in a Group Conducted by Female Leaders
}

\author{
Diane R. Follingstad \\ University of South Carolina - Columbia, follingstad@uky.edu \\ Peter R. Kilmann \\ University of South Carolina, kilmann@sc.edu \\ Elizabeth A. Robinson \\ University of South Carolina
}

Follow this and additional works at: https://uknowledge.uky.edu/crvaw_facpub

Part of the Psychology Commons

Right click to open a feedback form in a new tab to let us know how this document benefits you.

\section{Repository Citation}

Follingstad, Diane R.; Kilmann, Peter R.; and Robinson, Elizabeth A., "Prediction of Self-Actualization in Male Participants in a Group Conducted by Female Leaders" (1976). CRVAW Faculty Journal Articles. 64. https://uknowledge.uky.edu/crvaw_facpub/64

This Article is brought to you for free and open access by the Center for Research on Violence Against Women at UKnowledge. It has been accepted for inclusion in CRVAW Faculty Journal Articles by an authorized administrator of UKnowledge. For more information, please contact UKnowledge@lsv.uky.edu. 
Prediction of Self-Actualization in Male Participants in a Group Conducted by

Female Leaders

Digital Object Identifier (DOI)

http://dx.doi.org/10.1002/1097-4679(197607)32:3<706::AID-JCLP2270320347>3.0.CO;2-R

Notes/Citation Information

Dr. Diane Follingstad had not been a faculty member of the University of Kentucky at the publication time. 


\title{
PREDICTION OF SELF-ACTUALIZATION IN MALE PARTICIPANTS IN A GROUP CONDUCTED BY FEMALE LEADERS ${ }^{1}$
}

DIANE R. FOLlingstad, ${ }^{2}$ PETER R. KILMANN AND ELIZABETh A. ROBINSON

\author{
University of South Carolina
}

\section{Problem}

Some evidence indicates that males prefer male over female counselors when asked to state a preference $\left(e . g .{ }^{(2,14)}\right)$. The reasons for this preference vary, but male counselors usually are attributed with greater trust, respect, and admiration (2). The literature on the authoritarian personality suggests that highly authoritarian persons tend to hold more traditional stereotypes with regard to male-female sex role behavior than persons who score lower in authoritarianism(e.g., (1)). Thus, it follows logically that males who score high in authoritarianism and reflect traditional attitudes toward women might not accept the authority and competence of female counselors and therefore might resist their treatment inputs. This hypothesized reaction should have a negative or no effect on outcome for these persons. By contrast, males who report lower authoritarian scores and greater agreement with profeminist attitudes before treatment should show a more positive treatment outcome when exposed to female counselors.

This study attempted to predict which male $S$ s would reflect higher selfactualization scores when exposed to a 16-hour marathon group conducted by female leaders. In this regard, prior studies have found positive changes in selfactualization as a function of a 16-hour marathon group experience (e.g., (7, 8)). Furthermore, the "isolated" nature of marathon treatment permits the $E$ to place greater confidence in the assumption that the impact of treatment is not confounded with "therapeutic" inputs from informal contacts with persons outside the group. The three predictor scales measured authoritarianism, attitudes toward women, and need for social approval. An attempt also was made to determine whether males who score low in authoritarianism, reflect greater agreement with profeminist attitudes, and report a high need for social approval would rate the leader and the group experience more positively.

\section{METHOD}

Subjects. The $S$ s were 25 male volunteers who were enrolled in an undergraduate psychology class. Ss were selected randomly from a male and female student population that had volunteered to participate in a 16-hour marathon group. The group was described as having the purpose of greater self-understanding and self-awareness. Before they volunteered, $S$ s were told that the composition of their group would be either all male, all female or mixed. The mean age of the entire sample was 21.3 , with a range from 18 to 32 years.

Treatment. The two marathon groups were conducted by the same leader team, which consisted of a female who holds the doctorate in clinical psychology and a female predoctoral candidate in clinical psychology. The former leader took primary responsibility for directing the treatment format, while the second leader functioned as an adjunct facilitator. The two leaders had conducted a number of marathon groups together prior to this experiment. The leaders decided upon the sequence of group exercises prior to the beginning of the marathons and thereby controlled the treatment format in both groups.

The treatment consisted of a structured personal growth group experience. The role of the leaders was to involve group members in structured exercises designed to enhance interpersonal trust and involvement. The leaders and the

1The authors would like to acknowledge the statistical consultation of Joan M. Combes.

2Requests for reprints should be sent to Diane R. Follingstad, Department of Psychology, University of South Carolina, Columbia, S.C. 29208. 
participants discussed alternative ways to handle interpersonal situations. Communication exercises, relaxation exercises, and sensory awareness experiences also were used within a here-and-now framework. Some time was allowed for discussion of sex roles and male-female relationships. Although the leaders helped steer the discussion toward these areas, they attempted to avoid introjecting their own personal philosophies on the subject matter. Participants received feedback on how they were perceived by the leaders and group members at the end of the marathon.

Measures. The California F-Scale (Revised Version). A revised version of the California F-Scale (Form (40/45), originally developed by Adorno, et al. ${ }^{(1)}$, was used to measure ethnic prejudice and "prefascist tendencies." The revised form consists of 30 items and was meant to be an improved and shorter version of the original $F$ Scale by including negatively worded items to control for an acquiescent response set. The test is scored in terms of whether the respondent agrees or disagrees with each statement (see Robinson and Shaver(11)).

The Attitudes toward Women Scale (AWS). The AWS, developed by Spence, Helmreich, and Stapp ${ }^{(16)}$, is a 25 -item Likert-type scale that contains statements related to women's rights and roles in vocational, educational, intellectual, social and sexual activities, and marital relationships and obligations. Each item has four response alternatives that range from agree strongly to disagree strongly. Spence, Helmreich and Stapp ${ }^{(15)}$ reported that this shortened version of the AWS correlated .95 with the original 55-item AWS. Each item was given a score from 0 to $3 ; 0$ represented the most traditional and 3 the most contemporary, profeminist response.

The Personal Orientation Inventory (POI). The POI was developed by Shostrom $(12,13)$ to measure personality characteristics associated with "positive mental health." Foulds and Warehime ${ }^{(5)}$ demonstrated that the POI is considerably resistant to a "fake good" response set, which is somewhat unusual among selfreport measures. Other studies have established concurrent validity for the POI $\left(e . g .,^{(6,}, 9\right)$. The test-retest reliabilities of the test range from .52 to $.82^{(13)}$.

The test consists of 150 two-choice comparative value statements that form 12 scales. Shostrom ${ }^{(13)}$ suggested that the scores of the two main scales that include all the items, Time Competence and Inner Directed, can be used as indices of self-actualization. This was recommended by Marks, Conry, and Foster ${ }^{(10)}$. The Time Competence scale is interpreted as measuring the ability to live meaningfully in the present, while the Inner Directed scale taps an independent, self-supportive orientation. An increase in score on the scales was the criterion of member growth.

The Marlowe-Crowne Social Desirability Scale (MCSDS). The MCSDS, developed by Crowne and Marlowe ${ }^{(3,4)}$, was used as a measure of need for social approval. The test consists of 33 true-false items with scores that range between 0 (low need to appear socially desirable) to 33 (high need to appear socially desirable). Crowne and Marlowe reported test-retest and internal consistency reliability coefficients of .88 . The instrument was administered because the demand characteristics of the experiment might have influenced males' self-reports of their attitudes toward women. Thus, the MCSDS was used as a check for an acquiescent response set.

Participant ratings of the leader. A 6-point, 28-item bipolar rating scale was constructed that tapped participant perceptions of: (a) leader characteristics (e.g., honest-dishonest, interesting-uninteresting, spontaneous-controlled); (b) leader approach (e.g., caring-detached, sensitive-insensitive, personal-impersonal, expresses warmth-expresses coolness); (c) leader competence (e.g., trustworthyuntrustworthy, expert-amateur, not easily threatened-easily threatened); (d) sexist characteristics of leader (e.g., passive-aggressive, emotional-rational); (e) 
the role of the leader in the group (e.g., influential-uninfluential, included-excluded, central in group-peripheral in group); and (f) masculinity-femininity of leader. The participants were instructed to respond to the primary leader. This scale was administered at the posttest.

Participant ratings of the group. A 6-point, 18-item bipolar rating scale also was constructed that assessed participant perceptions of: (a) the perceived effect of the group on the individual (e.g., personally useful-not personally useful, satisfying-unsatisfying); (b) the group process (e.g., friendly-unfriendly, supportivepunitive, cohesive-not cohesive); and (c) the effectiveness of the group (e.g., constructive-destructive, successful-unsuccessful). This scale was administered at the posttest.

Procedure. The two marathon groups were conducted one weekend apart, and the same procedure was used at both times. Ss were assigned randomly to the two marathon groups or to the no-treatment control group before pretesting.

$S$ s responded to the test measures 3 days before the beginning of the marathon. At that time none of the Ss knew whether they were in the marathon or control conditions or whether their group would be composed of all male, all female, or male-female $S \mathrm{~s}$. After pretesting, the $S \mathrm{~s}$ who were assigned to the marathon condition were instructed to report to the Psychological Service Center of the University of South Carolina 3 days later. The control Ss were instructed to report for posttesting 5 days later.

The time of each 16-hour marathon was from 8:00 A.M. Sunday morning until 12:00 P.M. that night. The marathon and control $S$ s responded to the postmeasures 2 days after the marathon, at which time the marathon Ss also rated the primary group leader and the group experience. All $S$ s again responded to the measures 4 weeks after the posttest. Thus, the California F scale, the AWS, the POI, and MCSDS were administered at three different times to experimental and control Ss.

\section{Results}

The two marathon groups were conducted by the same leader dyad, and the treatment format was the same across both groups. Therefore, it seemed reasonable to combine the $S \mathrm{~s}$ in the two marathons into one experimental condition. This procedure was supported by the fact that no significant differences were found between the two marathon groups on any of the variables used.

An analysis of covariance with the pretest as the covariate was used to determine whether the scores on the three predictor variables (California F scale, AWS, MCSDS) differentially changed between the pretest and posttest, and between the pretest and the follow-up as a function of treatment condition. No significant difference between marathon and control $S$ s was found on the California F scale on the posttest $(F<1)$ or on the follow-up $(F<1)$. Similarly, no significant difference was found on the MCSDS on the posttest $(F<1)$, or on the follow-up $(F(1,22)=1.07, p>.05)$. However, on the AWS, a highly significant group effect was found between the treatment and no-treatment conditions on the posttest $(F(1,22)=18.01, p<.001)$. This finding was due to the fact that the control $S_{s}$ ' attitudes toward women became more traditional over time, while the scores of the marathon $S$ s remained relatively stable across the first two testing periods. However, the difference between the two conditions became nonsignifcant at the follow-up $(F(1,22)=1.76, p>.05)$.

The data then were analyzed by means of a stepwise multiple regression program. Specifically, the program assigned independent status to the marathon $\mathrm{Ss}^{\prime}$ pretest scores on the California $\mathrm{F}$, the AWS, and the MCSDS to determine whether the amount of variance accounted for was significant. The dependent variables were the posttest and follow-up self-actualization scores. 
Pearsonian intercorrelations among the predictors at the pretest for the marathon Ss are shown in Table 1, as well as correlations of each predictor variable with outcome (increase in self-actualization). Table 1 shows that the scores of the

Table 1. Correlational Matrix That Shows Interrelationships of Predictor Variables With Each Other and with OUTCome

\begin{tabular}{lccr}
\hline Variable & California F & AWS & Marlowe-Crowne \\
\hline California F & - & $-.46^{*}$ & .14 \\
AWS & - & - & -.20 \\
Outcome (Self-Actualization) & & $.52^{*}$ & -.17 \\
$\quad$ Time Competence Posttest & $-.43^{*}$ & $.59^{* *}$ & .07 \\
Time Competence Follow-up & -.38 & $.56^{* *}$ & .07 \\
Inner Directed Posttest & $-.65^{* *}$ & $.51^{*}$ & .06 \\
Inner Directed Follow-up & $-.62^{* *}$ & & \\
\hline
\end{tabular}

${ }^{*} p<.05 ;{ }^{* *} p<.01$

California F scale and the AWS were statistically related $(r=-.46, p<.05)$, while the California F scale and the MCSDS $(r=.14, p>.05)$, and the AWS and MCSDS $(r=.20, p>.05)$, were statistically independent. Thus, as might be expected, there was a significant relationship between higher authoritarian scores and traditional attitudes toward women. It should be noted that the California $F$ and AWS scores do not appear to be a function of a socially desirable response set.

Table 1 shows that pretest scores of the predictors that significantly correlated with an increase on the Time Competence scale were (a) lower authoritarianism (California F) on the posttest and (b) greater agreement with profeminist attitudes (AWS) on the posttest and follow-up. Individual predictors significantly correlated with an increase on the Inner Directed scale were (a) lower authoritarianism (California $F$ ) on the posttest and follow-up and (b) greater agreement with profeminist attitudes (AWS) on the posttest and follow-up. The relationship of the MCSDS with self-actualization was random.

A summary of the multiple regression analysis is shown in Tables 2 and 3 . Table 2 shows that a higher AWS score was the greatest contributor to a higher

Table 2. Summary of Multiple Regression Analysis at Posttest and Follow-up on Time COMPETENCE

Time Competence

Variable Cumulative $\mathrm{R} \quad$ Cumulative $\mathrm{R}^{2} \quad$ Beta Weights

$\begin{array}{lllr}\text { Posttest } & & & .50 \\ \text { AWS } & .52 & .27 & -.24 \\ \text { Marlowe-Crowne }^{2} & .59 & .35 & -.17 \\ \text { California F } & .61 & .37 & .53 \\ \text { Follow-up } & & & -.14 \\ \text { AWS } & .59 & .35 & - \\ \text { California F } & .61 & .37 & - \\ \text { Marlowe-Crowne } & - & - & \end{array}$

Note: $F(3,13)=2.55, p>.05$ at posttest. $F(2,14)=4.06, p<.05$ at follow-up.

'Higher scores indicate greater agreement with profeminist attitudes.

${ }^{2}$ Higher scores indicate greater need for social approval.

'Higher scores indicate greater authoritarianism. 
Time Competence score on the posttest and the follow-up. The Ss' MCSDS scores were unrelated to outcome on the follow-up. Table 3 shows that a lower California $F$ score was the greatest contributor to a higher Inner Directed score on the posttest and the follow-up.

Table 3. Summary of Multiple Regression Analysis at Posttest and Follow-up on InnerDIRECTED

INNER-DIRECTED

$\begin{array}{llll}\text { Variable } & \text { Cumulative } \mathrm{R} & \text { Cumulative } \mathrm{R}^{2} & \text { Beta Weights }\end{array}$

\begin{tabular}{lllr}
\hline Posttest & & & -.52 \\
California F2 & .65 & .43 & .31 \\
AWS $^{2}$ & .71 & .51 & .08 \\
Marlowe-Crowne & .72 & .52 & \\
Follow-up & & & -.48 \\
California F & .62 & .39 & .30 \\
AWS & .67 & .45 & -.06 \\
Marlowe-Crowne & .67 & .45 &
\end{tabular}

Note: $F(3,13)=4.68, p<.05$ at posttest. $F(3,13)=3.57, p<.05$ at follow-up.

${ }^{1}$ Higher scores indicate greater authoritarianism.

${ }^{2}$ Higher scores indicate greater agreement with profeminist attitudes.

'Higher scores indicate greater need for social approval.

The cumulative correlation for the three predictors on the Time Competence scale was .61 on the posttest $(F(3,13)=2.55, p>.05)$ and .61 on the follow-up $(F(2,14)=4.06, p<.05)$. Thirty-seven percent of the variance on the posttest and $37 \%$ of the variance on the follow-up was accounted for. It should be noted that the AWS score made a significant contribution $(F(1,15)=4.89, p<.05)$ on the follow-up, which accounted for $35 \%$ of the variance.

With regard to the Inner Directed scale, Table 3 shows that the cumulative correlation for the three predictors was .72 on the posttest $(F(3,13)=4.68, p<$ $.05)$ and .67 on the follow-up $(F(3,13)=3.57, p<.05)$. Fifty-two percent of the variance on the posttest and $67 \%$ of the variance on the follow-up was accounted

Table 4. Correlational Matrix Showing Interrelationships of Predictor Variables with Participant Ratings of Leader and the Group

Participant Ratings

California F

Predictor Variables

Leader

Positive Personal Characteristics

AWS

Marlowe-Crowne

Positive Group Approach

Competence

Sexist Characteristics

Place In Group

Masculine-Feminine

$\begin{array}{lrc}.12 & .18 & .18 \\ .16 & .39 & .25 \\ .27 & .14 & .41^{*} \\ .21 & -.27 & -.31 \\ .07 & -.16 & .34 \\ .18 & -.01 & .47^{*}\end{array}$

Group

Assessed Effect On Individual

.02

.01

$-.18$

Positive Group Process

.20

.09

Effectiveness 
for. The California F. score made a significant contribution on the posttest (F (1, $15)=5.41, p<.05)$, which accounted for $42 \%$ of the variance.

Pearsonian intercorrelations among the six ratings of the leader, the three ratings of the group, and the predictors are shown in Table 4. Significant positive relationships were found between need for social approval and (a) positive ratings of leader competence, (b) ratings of the leader toward the feminine pole of the masculine-feminine scale. A significant correlation was found between higher participant ratings of group effectiveness and (a) lower authoritarianism, and (b) greater profeminist attitudes. It should be noted that there was a wide range in the correlation of the participant ratings of the leader and the group with each other (.01 to .84).

\section{Discussion}

This study found that males who reported greater agreement with profeminist attitudes prior to treatment showed a greater present orientation (POI scale "Time Competence") at the follow-up. Males who reported lower authoritarianism before the group experience reflected a greater independent, self-supportive outlook (POI scale "Inner Directed") at the posttest and at the follow-up. Thus, these males reflected higher levels of self-actualization after the group as defined by these POI scales ${ }^{(13)}$. This study also found that $S$ s with a greater need for social approval prior to treatment rated the leader as more competent and more feminine. In addition, $S$ s who reflected lower authoritarian scores and greater agreement with profeminist attitudes prior to treatment rated the group as more effective. Therefore, the Ss who showed the highest self-actualization scores also reported the group to be more effective than those who reflected lower scores.

The control $S$ s in this study shifted toward more traditional attitudes toward women, which did not occur for the marathon Ss. This finding suggests that among male college students, a shift toward more traditional attitudes toward women occurs that is inhibited by marathon treatment. For this reason the California $F$ score may be a more reliable predictor variable of males' responsiveness to female leaders. Future research should obtain pre- and post-experimental behavioral ratings of male-female interactions by naive but trained observers to determine the behavioral correlates of males' attitudes toward women.

Before any suggestions can be made that female counselors may be contraindicated for males who reflect traditional attitudes toward women and higher authoritarianism prior to treatment, future studies should use male leaders in similarly designed experiments. Additional investigations that use larger samples are needed to determine whether the predictive effects found in this study are only operative in a marathon growth group format or whether they generalize to: (a) male patient populations; (b) other treatment formats (i.e., weekly groups, individual sessions); and (c) outcome criteria other than increased self-actualization. It also would be important to determine whether female participants similarly respond differentially to female leaders as a function of their pretreatment authoritarian and attitudes toward women scores.

Prior studies have found that value-system similarity between client and counselor facilitated a positive outcome $\left(e . g .,{ }^{(16)}\right)$. If the findings of studies in this area are generalizable to the experimental design used in the present study, it seems logical that the more divergent or convergent the sex-role related attitudes between female leaders and male participants, the greater the negative or positive effect, respectively, on outcome. In order to investigate these aspects of the participant-leader pairing, future studies should obtain participants' postexperimental perceptions of leaders' attitudes. A similarity-dissimilarity index could be computed between these data and participants' ratings of their own attitudes, and the corresponding effect on outcome then could be examined. This procedure would determine whether $S$ s whose attitudes are most congruent with the leaders' attitudes show the greatest treatment gains. It also would be meaningful to obtain 
ratings of the leaders' treatment behavior to determine the manner in which leader attitudes are communicated in the treatment process.

\section{SUMmaRY}

This study attempted to predict which male $S_{s}$ would reflect higher selfactualization scores aiter participation in a 16-hour marathon group conducted by a female leader team. Twenty-five male undergraduates were assigned randomly to one of two marathon groups or to a no-treatment control group. The same female leader team conducted both groups according to the same treatment format. The three predictor scales measured authoritarianism, attitudes toward women, and need for social approval. Participants who showed the highest self-actualization scores at the posttest and at the follow-up rated the group more effective, scored lower in authoritarianism, and held greater agreement with profeminist attitudes.

\section{REFERENCES}

1. Adorno, T. W., Frenkel-Brunswik, E. Levinson, D. J. and Santord, R. M. The Authoritarian Personality. New York: Harper \& Row, 1950.

2. Chesler, P. Men drive women crazy. Psychol. Today, 1971, 5, 97-98.

3. Crowne, D. P. and Marlowe, D. A new scale of social desirability independent of psychopathology. J. consult. Psychol., 1960, 24, 349-354.

4. Crowne, D. P. and Marlowe, D. The Approval Motive. New York: John Wiley, 1964.

5. Fould, M. L. and WAREHIme, M. Effects of a "fake good" response set on a measure of selfactualization. J. counsel. Psychol., 1971, 18, 279-280.

6. Fox, J., KNaPP, R. R. and Michael, W. B. Assessment of self-actualization of psychiatric patients: Validity of the Personal Orientation Inventory. Educ. psychol. Meas., 1968, 28, 565-569.

7. Kilmann, P. R., Albert, B. M. and Sotile, W. M. The relationship between locus of control, structure of therapy, and outcome. J. consult. clin. Psychol., 1975, 48, 588.

8. Kilmann, P. R., Follingstad, D. R., Price, M. G., Rowland, K. F., and Robinson, E. A. Effects of a marathon group on self-actualization and attitudes toward women. J. clin. Psychol., 32, 154-157.

9. KNAPP, R. R. Relationship of a measure of self-actualization to neuroticism and extraversion. J. consult. Psychol., 1965, 29, 168-172.

10. MARKs, S. E., ConRY, R. F. and Foster, S. F. The marathon group hypothesis: An unanswered question. J. counsel. Psychol., 1973, 20, 185-187.

11. Robinson, J. P. and Shaver, P. R. Measures of social psychological attitudes. Ann Arbor: University of Michigan, Institute for Social Research, 1973.

12. Shostrom, E. A. A test for the measurement of self-actualization. Educ. psychol. Meas., 1965, $24,207-218$.

13. Shostrom, E. A. Manual for the Personal Orientation Inventory. San Diego, Calif.: Educational and Industrial Testing Service, 1966.

14. Simon, W. Age, sex, and title of therapist as determinants of patient's preferences. J. Psychol., $1973,83,145-149$.

15. Spence, J. T., Helmrich, R. and Stapp, J. A short version of the Attitudes Toward Women Scale (AWS). Bull. Psychonomic Soc., 1973, 2, 219-220.

16. Welkowitz, J., Cohen, J. and Ortmeyer, D. Value systems similarity: Investigation of patient-therapist dyads. J. consult. Psychol., 1967, 31, 48-55. 
Copyright of Journal of Clinical Psychology is the property of John Wiley \& Sons Inc. and its content may not be copied or emailed to multiple sites or posted to a listserv without the copyright holder's express written permission. However, users may print, download, or email articles for individual use. 